\title{
pÿApplying Affordances Scale as a Design Method Case Virtual Reality Course Design
}

\section{Holopainen, Jani}

University of Hawai'i at Manoa

2021

Holopainen , J , Lähtevänoja , A , Sandström , N , Nevgi , A , Mattila , O , Pöyry , E \& pÿParvinen , P 2021, Applying Affordances Scale as a Design Method Case Virtual Reality Course Design . in Proceedings of the 54th Hawaii International Conference on System Sciences . Proceedings of the Annual Hawaii International Conference on System Sciences, University of Hawai'i at Manoa, Honolulu , pp. 14-23, Hawaii International Conference on System Sciences , Hawaii , United States , 04/01/2021 . https://doi.org/10.24251/HICSS.2021.003

http://hdl.handle.net/10138/328486

https://doi.org/10.24251/HICSS.2021.003

cc_by_nc_nd

publishedVersion

Downloaded from Helda, University of Helsinki institutional repository.

This is an electronic reprint of the original article.

This reprint may differ from the original in pagination and typographic detail.

Please cite the original version. 


\section{Applying Affordances Scale as a Design Method - Case Virtual Reality Course Design}

\author{
Jani Holopainen \\ University of Helsinki \\ jani.m.holopainen@helsinki.fi
}

\author{
Anne Nevgi \\ University of Helsinki \\ anne.nevgi@helsinki.fi
}

\author{
Antti Lähtevänoja \\ University of Jyväskylä \\ antti.lahtevanoja@helsinki.fi
}

\author{
Osmo Mattila \\ UEF \\ Essi Pöyry \\ University of Helsinki \\ osmo.mattila@helsinki.fi essi.poyry@helsinki.fi
}

\author{
Niclas Sandström \\ University of Helsinki \\ niclas.sandstrom@helsinki.fi \\ Petri Parvinen \\ University of Helsinki \\ petri.parvinen@helsinki.fi
}

\begin{abstract}
Practitioners including designers and teachers developing Virtual Reality (VR) courses are facing a question regarding the strengths and subject areas in which VR-enriched courses might have the highest potential compared to conventional courses. The present study develops a survey scale to assess and match industry managers' requirements for skills for working life. The same scale was surveyed among two different groups of higher education students participating in conventional courses and a VR-aided course. The results indicate that the industry requirements were higher than met by the both course types. However, the results highlight a set of skills for which the VR courses have the highest potential compared to conventional courses. These skills include self-monitoring, independent thinking and understanding, adapting and applying new ideas into practice as well as creativity as a latent class theme. The paper discusses example designs based on these skills whose development is suggested to be included in the future VR course designs.
\end{abstract}

\section{Introduction}

The concept of affordances is widely applied in both Information System (IS) research and educational research. By definition, affordances are not only system properties but rather relations and dynamic interactions between the system and its users [1]. Bernhard et al. [2] describe the affordances as a process consisting of four stages: affordance existence, affordance perception, affordance actualization and affordance effect. This classification was also applied in a literature review by Pozzi et al. [3] to categorize the existing affordance literature. The literature review concludes that the majority of the existing research is describing various system features as potential for action, hence concentrating on the affordance existence phase [3].

Inspired by the literature review by Pozzi et al. [3] we conducted a similar review in this study, but with the focus on the Virtual Learning Environments (VLEs). According to Dillenbourg et al. [4], VLE is a designed information and social place varying from text to immersive 3D worlds. VLEs are not restricted to distance education and they integrate heterogeneous technologies, multiple pedagogical approaches and overlap with physical environments. Virtual Reality based Learning Environment (VRLE) is a specification of VLE where the technology is Virtual Reality (VR). VR is defined by Milgram and Kishino [5] as an artificial, computer-generated environment where users can interact with the environment. In this study when we talk about VR, we refer to an environment and technology that is consumed with head-mounted displays (HMDs).

Our literature review findings are in line with Pozzi et al. [3] showing that the most of the VLEs affordance research is concentrating on the affordance existence phase, but there is also research describing the other phases of the affordance process. However, what is missing is using the affordances concept as a guiding principle in the design. According to the definition, the Design Science Research (DSR) aims to invent new designs and means to improve the existing systems [6, 7]. The strength of DSR in IS science is its multidisciplinary and holistic approach in creating and testing new techniques and technologies [8]. DSR develops theoretically grounded and fieldtested socio-technical artifacts, including constructs, models, methods, instantiations or design theories [9, 10]. Further, the accumulating design knowledge guides researchers and practitioners including designers, developers and managers among others on 
how to build innovative solutions to important problems [10]. Considering the research gap identified in the literature review and definition for the DSR, the objectives of this study are 1) introducing new means to apply the affordances concept as a design method, and 2) to introduce theoretically grounded and fieldtested artifacts and a system design framework to develop VLEs.

In order to fulfill these objectives, first, we adopt the Cognitive Affordances of Technologies framework (CAT) [11]. Adopting the CAT framework, we developed a survey to evaluate manager-level industry company workers around the globe (forest harvester manufacturer) and their perceptions about the skills for working life most crucial in their work. The same survey was adopted to evaluate higher education students on courses preparing for similar manager level industry positions that were surveyed earlier. One of these courses was a Virtual Reality (VR) -aided course on machinery.

Our study introduces a design science research method based on the affordance framework, applicable in future research and development of VLEs. The study results also pinpoint skills that the conventional courses are lacking the most, as well as skills the VR courses have the highest potential in promoting. All this can help practitioners, including designers and teachers, developing VR courses and reflecting on what the strengths and subject areas are, or in what contexts VR might have the highest potential compared to conventional courses.

\section{Literature review}

Bernhard et al. [2] describes the affordances as a process: affordance existence, affordance perception, affordance actualization and affordance effect. Our literature review introduces VLE affordances literature referring to the affordance process.

Starting by the definition for affordance existence, Gibson [12] described that the affordances are natural relationships between the reality and users. Furthermore, while the affordances exist naturally, they are not necessarily visible, known or desired. Norman [13] differentiates between real and perceived affordances, arguing that until the affordance is perceived there is no utility for users. This conforms with Bernhard et al. [2] separating affordance existence before perception. According to the literature review by Pozzi et al. [3] considering the general affordances literature, most of the studies belong to this group. This group of literature introduces various technology and system features and what they might afford the users.
In terms of VLE studies considering affordance existence, Dalgarno and Lee [14] introduce the affordances, or "potential learning benefits of threedimensional virtual learning environments" in their words. Based on their literature review they suggest that representational fidelity, learner interaction, construction of identity, sense of presence and copresence afford various learning tasks (actions) which further lead to outcomes such as spatial knowledge representation, experiential learning, increased motivation and engagement, contextual learning and collaborative/social learning. They contend that research and development of VLEs concentrate more on their unique characteristics and learning benefits. Similarly, technical, immersive and social dimensions [15] as well as collaborative learning, avatar representation and learning space awareness [16] were identified affordances in conceptual assessments of Second Life VLEs. Like these examples, common for the studies in the affordance existence category is that they are theoretical or conceptual in nature. In addition, there is a bunch of VLE studies describing various system and technological features as potential for actions (e.g. $[17,18]$. What is missing in the VLE affordance field are empirical studies considering also the factors behind the affordance existence such as technology features as well as organizational goals and expertise identified in the general affordance research [19, 3, 20].

According to Greeno [21], the affordance perception includes external physical and internal mental processes. The following studies included in this category concentrate on user perceptions and related processes, but they also might consider actions or behaviors to a minor extent.

Bhargava et al. [22] compared perceived real life and VR affordances in terms of movement and passability. Their results suggest that the perceived affordances are similar in both environments. However, participants required more dynamic information, i.e. movement, in VR to reach the same level of perception about the environment and its affordances. In other words, this study suggests that while in the real life we can stand still and perceive affordances from the surroundings, in VR we have to move and gather more sensory effects and information before we can reach the same level of understanding. This study suggests that movement in VR can be a factor affecting affordance perception, while lack of movement or incapability to move is a restriction. Furthermore, Volkoff and Strong [19] suggest that affordance can have a dual role enabling or restricting perceptions and further actions.

Leyrer et al. [23] showed in their experiment that the use of an avatar and eye height in VR have a 
significant effect on the perceived dimensions and distances in VR. This implies that the affordance perception can be affected by these factors. Lin et al. [24] concluded that the inclusion of avatar contributes to more realistic perceptions and actions.

In a somewhat different VLE study by Chen et al. [25] they trained a computer using recording from 12 hours of human driving in a video game. Their algorithm considered mediated perception, direct perception and behavior reflex and this model made a good fit in various virtual driving environments. The result suggests that the affordance process [2], might also include different dimensions for affordance perception including mediated and direct perception. Similarly, also cognitive psychology [21,26] suggests that there might be indirect and direct perceptions before actions are taken. In addition, Gibson [27] suggests that perception-action can be a loop where actions can lead to new perceptions etc.

Therefore, in order to form a holistic picture about the affordance dynamics, different phases of the affordance process should be considered. For example, a study by Alshaer et al. [28] aimed to explain the factors behind perception, actions and outcomes in the context of VR-based driving simulators. In an experiment comparing HMDs and a monitor, the use of HMDs and immersion both affected perception and actions. In addition, users' ability to look around affected their actions and outcomes (i.e. performance). They also recognized that perceptions and actions can be misaligned or conflicting. Finally, they reported that presence is affected by all controlled variables including display type, ability to look around and inclusion of avatar.

In another study considering both perception but also actualization, Grechkin et al. [29] found that locomotion (walking vs. joystick) affected users' perceptions, but the display type (CAVE vs. HMD) did not. However, eventually both locomotion and display type had an effect on behavior and decision to take actions.

In terms of the affordance actualization, Greeno [21] suggests that affordance perceptions are preconditions for any activity and behavior or decisions not to act. A study by Karahanna et al. [20] provides empirical evidence that the fulfillment of psychological needs drives people to act and use affordances enabled by the technological features. Actions taken also in most of the cases fulfill the psychological needs and thus these needs are important factors for actions. As an example of VLE studies in this category, Hong et al. [30] found in their experiment that the VLE avatar facilitates search for useful functions, exploratory creativity as well as analysis and evaluation of functionality and usefulness.

Invitto et al. [31] compared training sessions and grasping things in real life and in VR i.e. grasping affordances. According to their findings, grasping things in VR create more visual brain activity and less attention and action planning activity compared to the real-life condition. This can imply that users do not pay attention to or contemplate their actions as well in VR compared to real-life. This implies that users are more uninhibited to take actions in VR also suggesting higher actualization rate in VR compared to real-life situations.

Dalgarno and Lee [14] surveyed teachers on students' VLE use. They found that three-dimensional virtual environments generated activities such as place and concept exploration, task practice, role play, gaming, instruction, communication and students were building or scripting stuff or creating and using slide shows and machinimas. Their results also suggest that the learning activity "instruction" led to learning outcomes or benefits including place familiarity and motivation and engagement.

According to a literature review on multi-user virtual environments, Mantziou et al. [32] propose free navigation, creation, modeling and simulation, multichannel communication, collaboration and cooperation and content presentation and/or delivery as affordances (existence) which furthermore can generate learning activities including content creation, content exploration and interaction with content, social interaction, gaming, participation in representations of real-life events and situations.

The actions and behaviors generate some kind of effects which further can be categorized in short- and long-term outcomes [33]. The outcomes can also include enabling conditions for additional affordances, development of additional IS features as well as organizational changes [19].

In terms of VLEs, Girvan and Savage [34] found that the Second Life VLE generated affordance outcomes that are aligned with the Communal Constructivism -learning approach. The results of Tsai et al. [35] suggest that VRLE media richness can contribute to perceived visibility and further on an intention to learn as an outcome. On the other hand, VRLE interactivity contributes to perceived compatibility but having no correlation to the intention to learn. Zheng et al. [36] studied affordance for collaborative learning as outcome. They build their findings based on a literature review and suggest that interaction, imagination and immersion are the technological features creating actions such as social interaction, knowledge construction and resource sharing. All this can generate collaborative learning. 
Diaz et al. [37] concluded that there are no differences between high and low fidelity HMDs on users' satisfaction and experience or in spatial and experiential learning which they considered as outcomes.

\section{Theoretical framework}

We identify the research gaps in the current VLE affordance research by considering the requirements and prospects provided by the DSR. First, considering the requirement of DSR about the holistic system approach [8], we can say that the current VLE studies are rarely considering the whole affordance process. However, we must admit that such a holistic approach is difficult to carry out, and also outside our research scope, as our study considers mainly the affordance existence and perceptions.

Another requirement for DSR about inventing new designs and means to improve the existing systems [6, 7] is also not addressed among the existing VLE affordance studies, as the research field lacks experiments or comparisons identifying the unique features of VLEs compared to conventional approaches. In terms of ways to improve the existing systems, the research field lacks adoption and development of design methods. Our study will contribute to these issues as we compare conventional courses, a VR-aided course and working life requirements as well as apply and develop an affordances scale as a design method.

The literature review revealed a lack of empirical research developing models and structures explaining the VLE affordance process, i.e. existence, perception, actualization and effects. As the main purpose of DSR is to explain how to build innovative solutions to important problems [10], also modelling has an important role in this development process [6]. Our study will contribute by distinguishing some factors behind the affordance existence and perception.

We also learned that among the VLE affordance studies, the artifact designs are rarely theoretically grounded and field-tested as typical for DSR [9, 10]. Field testing can reveal some unexpected results also in terms of restricting nature of affordances [19], a dimension that was only slightly researched previously. Our study builds on field-testing an instrument based on the CAT framework [11]. The original CAT framework and scale was developed to be used for identifying what kind of cognitive affordances the observed technology-supported learning environment provided, and it consists of seven categories including experimental learning, discourse/dialogic learning, supportive learning, learning by doing, critical thinking, conceptual change and self-regulated learning [11]. Each category consists of four to nine cognitive criteria (a total of 47 cognitive criteria), which were adapted to fit our study context.

Considering these gaps and research contributions, the objectives of this study are 1) introducing new means for the application of the affordances concept as a design method, and 2) to introduce theoretically grounded and field-tested artifacts and a system design framework to develop VLEs. These objectives also fulfill the research question puzzling many practitioners including designers and teachers developing VR courses in the field: What are the strengths and subject areas in which VR courses might have the highest potential compared to conventional courses?

\section{Data and methodology}

The data were collected by an electronic questionnaire from three groups: 1) manager-level industry company workers around the globe (forest harvester manufacturer $)(n=57), 2)$ conventional engineering courses in four different European Universities $(n=49), 3)$ a VR-aided course on machinery in one Finnish University of Applied Sciences $(n=32)$. The electronic questionnaire consisted of demographic background questions and the CAT instrument with seven scales: experimental learning ( 9 items), discourse/dialogic learning (4 items), supportive learning ( 7 items), learning by doing (5 items), critical thinking (5 items), conceptual change (9 items) and self-regulated learning (8 items)

The conventional engineering courses included elements such as web-based instructions, assignments and references as well as face-to-face lectures and group work. Some courses had industry cases on which the students worked for solutions in terms of circular economy and value engineering. In addition to those, the VR-aided course included a VR application which was used by the students in small groups. The application included assembly and disassembly of a piece of industry machinery at the same time hearing and reading about the processes and functionalities. Each student experienced the application individually in VR with the HMD. At the same time, other students in the group followed and discussed what they saw on the computer screen (the same view played in the HMD) or what they just experienced themselves in VR.

The motivation behind selecting these groups was to set the goal level for teaching and developing the working life skills (Group 1). In addition, the conventional courses were evaluated to set the benchmark level (Group 2), while Group 3 was 
evaluated in order to pinpoint those areas where the VR-aided course design could better meet the requirements for skills for working life. In other words, the research setting and method followed the idea and interest to find out those areas of skills for working life where the conventional courses and VRaided courses differ from each other, and on the other hand, where one of these courses are able to meet the working life standards.

For the total sample $(n=138)$, we conducted exploratory factor analysis (Maximum Likelihood, Pro-max rotation) to reduce survey items and dimensions introduced in the initial CAT-framework difference only between one conventional course and the VR-aided course (but not between VR and other conventional courses).

\section{Results}

Table 1 presents the results of exploratory factor analysis with Maximum likelihood estimation and Promax rotation methods. Cross-loadings with a difference less than 0,2 and loadings under 0,5 were removed resulting a four-dimensional latent factor structure. The four dimensions for working life skills were named as Intrapersonal, Cognitive, Creativity

Table 1 The four dimensional structure on the explanatory factor analyses representing the latent factors of skills.

\begin{tabular}{|c|c|c|c|c|}
\hline Item Name & Intrapersonal & Cognitive & Creativity & Practicability \\
\hline Time management & $0,95^{1}$ & & & \\
\hline Creating strategies & 0,88 & & & \\
\hline Self-motivation & 0,69 & & & \\
\hline Setting goals & 0,65 & & & \\
\hline Monitoring self and own work e.g. book-keeping & 0,52 & & & \\
\hline Synthesizing e.g. combining things and solutions & & 0,90 & & \\
\hline Analytical thinking & & 0,68 & & \\
\hline Critical thinking & & 0,65 & & \\
\hline Searching information & & 0,65 & & \\
\hline Independent thinking and understanding & & 0,52 & & \\
\hline Presenting new ideas with practical examples & & & 0,93 & \\
\hline Adapting and applying new ideas into practice & & & 0,79 & \\
\hline Hands-on-work and performance & & & & 0,85 \\
\hline Practical skills and expertise & & & & 0,72 \\
\hline Eigenvalue & 6,11 & 1,37 & 1,24 & 1,17 \\
\hline Explained variance $\%$ & 43,61 & 9,76 & 8,85 & 8,33 \\
\hline Cronbach's alpha & 0,88 & 0,82 & 0,85 & 0,77 \\
\hline
\end{tabular}

as well as to identify the latent factor structure [38].

In order to find out difference between the subject groups we adopt a non-parametric Kruskal-Wallis method to make comparisons between all three subject groups and Mann-Whitney method to make pairwise comparisons [39]. These comparisons are made on both reduced number of survey items as well as extracted latent factors. As the conventional courses were four different courses in different universities, we also tested the differences between these institutions. Non-parametric comparisons revealed that in terms of items "Searching information" as well as "Independent thinking and understanding" the courses were not identical. The first item was significantly different between two conventional courses, whereas the second item showed significant and Practicability. All eigenvalues are above 1 and Cronbach's alphas above 0,77 indicating good reliability and consistency among the latent factors.

With the reduced CAT framework, all the items were compared between the groups. Figure 1 presents group-wise Kruskal-Wallis and pair-wise MannWhitney test results with statistically significant differences ( $I, C, V R, p=0,05)$. The results indicate that the industry managers' requirements for skills for working life are in all cases higher than met by the course designs. Industry requirements were statistically significantly higher compared to both course designs in the case of time management, selfmotivation, synthesizing, searching information, and in practical skills and expertise. These are the skill training areas that both conventional and VR-aided 


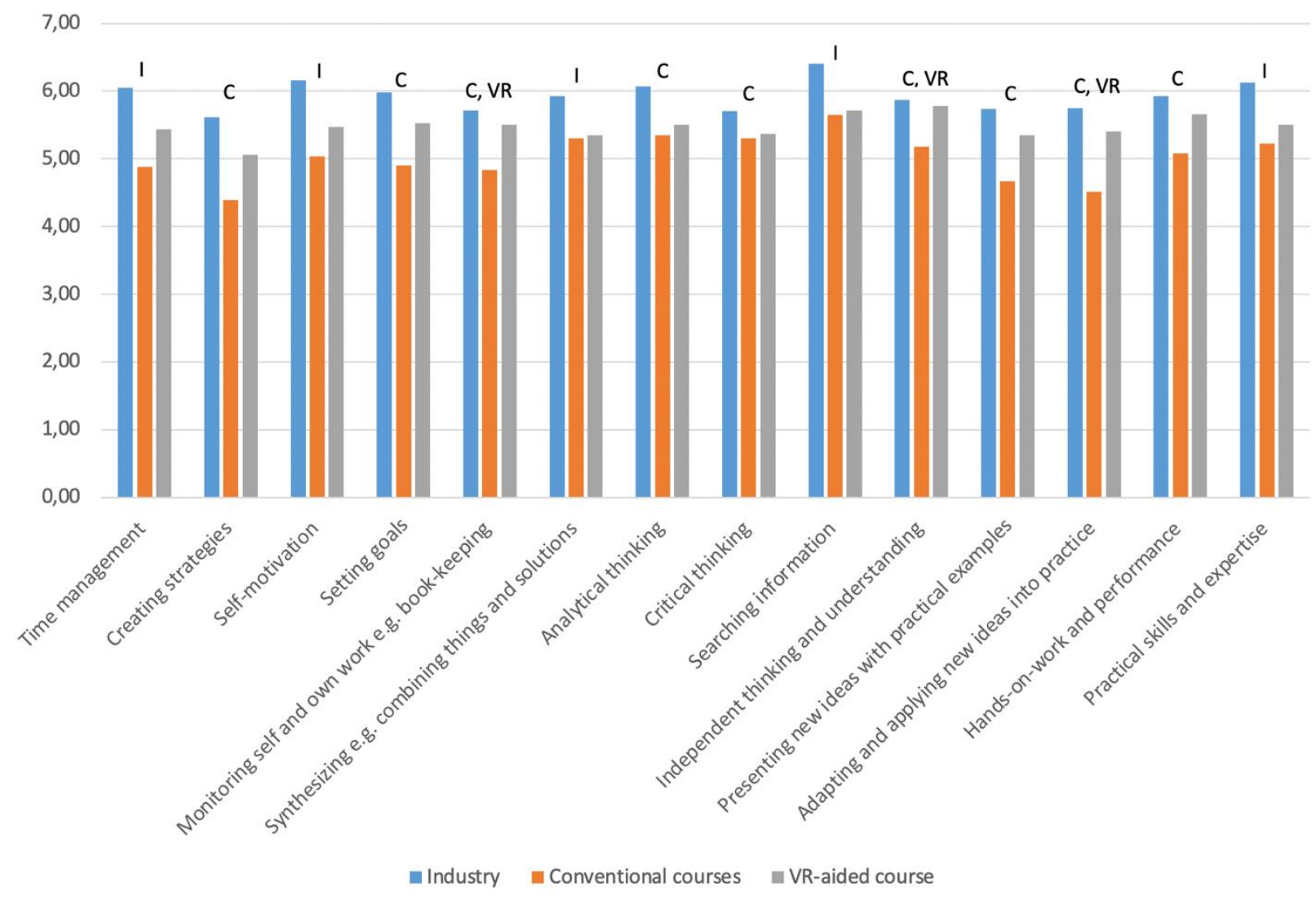

I = Industry different to both course designs, $C=$ Conventional courses different to industry design, VR = VR-aided course outperforms conventional courses

Figure 1. The reduced CAT framework items and significant differences $(p=0,05)$ among three subject groups including industry, conventional courses and a VR-aided course design.

courses should develop. In addition, the conventional course designs were significantly behind the industry requirements in the fields of creating strategies, setting goals, self-monitoring, analytical thinking, critical thinking, independent thinking and understanding, presenting new ideas with practical examples, adapting and applying new ideas into practice as well as in providing hands-on-work and performance training. These are the fields where conventional course designs are critically bending the industry working life requirements. In three skill-fields named self-monitoring, independent thinking and understanding as well as in adapting and applying new ideas into practice, the VR-aided course outperformed the conventional course designs.

However, the item "independent thinking and understanding" showed significant difference between only one conventional course and the VR-aided course. Nevertheless, these are the fields suggested to be included in the VR course designs.
The exploratory factor analysis revealed four latent factors including Intrapersonal, Cognitive, Creativity and Practicability -skills which also were compared between the groups (Figure 2). Factor scores were saved and compared group-wise in Kruskal-Wallis and pair-wise in Mann-Whitney tests. In Intrapersonal and Cognitive factors Industry showed higher results and statistically significant differences $(p=0,05)$ compared to conventional courses and VR-aided course. In these themes industry managers' requirement levels are higher than what has been provided by the educational institutions. In terms of Creativity and Practicability, conventional course designs were behind the industry requirements with statistical significance. VR-aided course outperformed conventional courses in terms of the creativity-factor dimension. This is the skill category, where VR-aided course has an improved potential to provide different and high standard skills for working life training. 


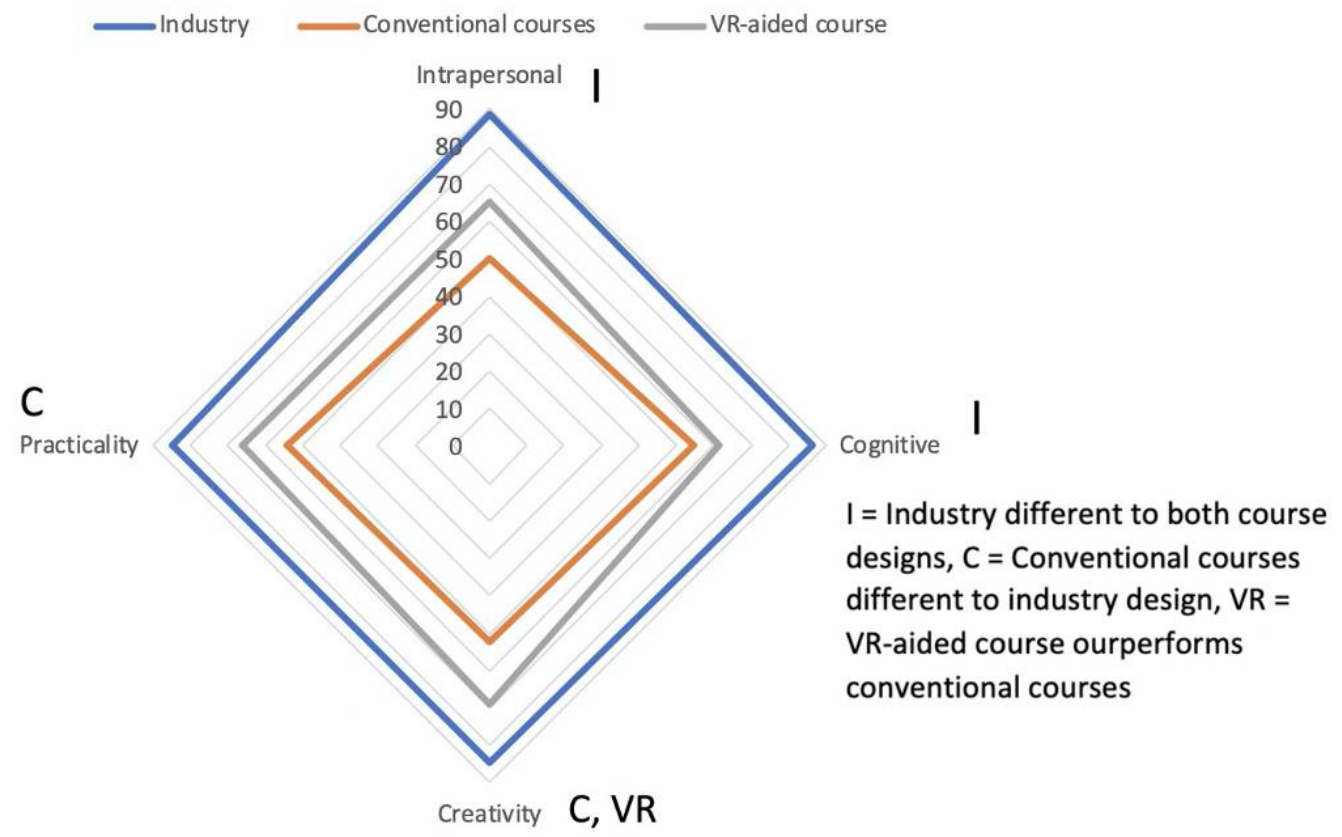

Figure 2. Factor score means on the axes and significant differences $(p=0,05)$ among three subject groups including industry, conventional courses and a VR-aided course design.

\section{Discussion and conclusions}

The literature review revealed that the VLE affordance research field is lacking experiments and comparison studies identifying the unique features of VLEs compared to conventional systems (also requested by e.g. [40]). In addition, there seemed to be a lack of adoption and development of design methods. Our study contributes to these shortcomings by comparing conventional courses, a VR-aided course and working life requirements as well as applying and developing an affordances scale as a design method.

The use of the scale revealed several new affordances and system design implications. Considering the individual scale items, the industry managers' requirements for work life skills were higher in all cases compared to the course designs. This implies low equivalence between higher education and skills for working life also addressed by some previous research [41, 42]. The conventional courses showed the lowest equivalence to the working life requirements. The VR-aided course performed somewhat better and closer to the industry requirements. For example, there were no statistical differences between the industry and VR in terms of creating strategies, setting goals, self-monitoring, analytical thinking, critical thinking, independent thinking and understanding, presenting new ideas with practical examples, adapting and applying new ideas into practice as well as in providing hands-on work and performance training. While the VR-aided course succeeded well in these areas compared to the conventional courses, it is too early to conclude that these are the suggested design principles to be included into VR course designs. Instead, the statistically significant differences between the conventional courses and the VR-aided course emerged on the items including self-monitoring, independent thinking and understanding as well as in adapting and applying new ideas into practice. Nevertheless, the item "independent thinking and understanding" showed significant difference only between one conventional course and the VR-aided course; these are the suggested fields with the highest potential to be included in the VR course designs. In addition, the VR-aided course showed potential within the creativity-skill category.

In terms of design, what does all this mean? To have "self-monitoring" elements on a VR-aided course could mean self-study reflections which were also used in the VR-aided course under research. The usual method is learning diaries that could be added also into the VR-aided courses reinforced with screen recordings captured from the individual's VR experience. In addition, various in-game analytics 
available in VR and game-engine environments could be made available to aid the self-study reflections.

Immersive multi-sensory environments such as VR guarantees strong engrams for its users $([15,35$, 43], that should be utilized also in course designs in terms of "independent thinking and understanding". As mentioned above, self-study reflections such as learning diaries is one way to do this. In addition, engrams are in the users' minds and they might activate spontaneously in different situations. It is therefore important that the learning objectives and engrams are braided so that when the engram hits the target it also reminds about the learning objective. For example, when a student is already in the work life and sees a machinery part first time in real-life, the engram built in VR should remind about the learning objectives [45] e.g. remembering, understanding, applying etc. This also requires research about the long-term effects of design elements and content, which is still missing in the VR research field.

Much of the VLE affordance research is highlighting the potential of VR in contextual learning (e.g. $[16,40]$ referring to "adapting and applying new ideas into practice". Modelling and presenting contents and spaces as well as allowing interactions in VR [36] is a way to do this, so that users can rehearse adapting and applying things. According to the research, people are less uninhibited to take actions in VR than in real-life [29, 31], so rehearsing and repeating in VR could also lower the threshold to take action in real-life. But what is the threshold in terms of details in models and presentation in VR, i.e. what is the benefit-cost ratio of modelling work? This is also something to be explored by future research. We also found "creativity" as one potential skill learning category in VR. In addition, previous research suggests many ways to do this. For example, avatar inclusion [30] and free navigation and interactivity [32] contribute to creativity in VR. However, a majority of the research is concentrating on technological aspects and features, but less focus is given to content, tasks and sociability factors in advancing creativity.

Our literature review also exposed lack of empirical studies considering the factors behind the affordance existence. In this study we identified that there are needs for working life skills that can be categorized in intrapersonal, cognitive, creativity and practicability -skills. Following Karahanna et al. [20] needs are also factors for affordance existence. Thus, we can suggest that the aforementioned needcategories for working life skills should be considered in any course designs aiming at developing also working life skills. For example, course objectives could include development of intrapersonal, cognitive, creativity and practicability -skills, which are further implemented in more detail in the course contents, methods and evaluations.

Currently, 21st century skills [44] are included as objectives in many curricula and course designs. The most common categorization of these skills is intrapersonal, cognitive and interpersonal, the last referring to various communication skills. According to many VLE affordance studies, communication and interaction affordances can be provided by VLEs [32, $36,14]$. However, as discovered in our study, communication and interaction affordances were found merely resulting from more latent factors such as creativity and practicality.

Teaching and training interpersonal i.e. communication skills are found to be very demanding in higher education but some technological solutions enabling various learning activities might promote these $[36,14]$. Our results suggest that in those course designs, the objectives should perhaps consider developing creativity and practicability more so than interpersonal / communication skills. Also, everyday life experience shows that people with high creativity and practicality are pretty good in reflection and expressing themselves, so this finding should be taken as a hypothesis to be tested by future research.

One of the most obvious limitations is that the levels between the subject groups are fundamentally different. For example, industry managers set their working life requirements higher throughout, compared to students evaluating the same items provided by the courses. The same applies to the different levels between the conventional courses and the VR-aided course. However, in our sample the analyses resulted in both significant and insignificant differences so the significant differences should be considered as we did. Also, among all courses, there is variation in terms of teaching objectives, content, methods, assessment and teachers' pedagogical approaches. In order to remove that bias, future studies should compare courses where all the parameters are constant except the treatment, e.g. the VR design. Nevertheless, this study is one of the first ones to compare conventional and VR courses in a real-life setting to the working life requirements, and to our knowledge, the first to exclusively and extensively consider skills as perceived outcomes for VR. Considering the infinite options that practitioners have in iterating and developing the VR course designs, we hope that our study paves the way for further guidance and applications. 


\section{Acknowledgements}

We thank Emma Luode-Clementino and Mari Korpi for the data collection effort during their master's theses as well as Leena Närhi for proofreading and editing.

\section{References}

[1] A. Majchrzak and M. L. Markus, "Technology affordances and constraints in management information systems (mis)," Encyclopedia of Management Theory, (Ed: E. Kessler), Sage Publications, 2012.

[2] E. Bernhard, J. C. Recker, and A. Burton-Jones, "Understanding the actualization of affordances: A study in the process modeling context," 2013.

[3] G. Pozzi, F. Pigni, and C. Vitari, "Affordance theory in the is discipline: A review and synthesis of the literature," 2014.

[4] P. Dillenbourg, D. Schneider, and P. Synteta, "Virtual learning environments," 2002.

[5] P. Milgram and F. Kishino, "A taxonomy of mixed reality visual displays," IEICE TRANSACTIONS on Information and Systems, vol. 77, no. 12, pp. 1321-1329, 1994.

[6] S. T. March and G. F. Smith, "Design and natural science research on information technology," Decision support systems, vol. 15, no. 4, pp. 251-266, 1995.

[7] H. A. Simon, The sciences of the artificial (3"edition), 1996.

[8] J. F. Nunamaker Jr, N. W. Twyman, and J. S. Giboney, "Breaking out of the design science box: High-value impact through multidisciplinary design science programs of research," 2013.

[9] T. S. McLaren, M. M. Head, Y. Yuan, and Y.E. Chan, "A multilevel model for measuring fit between a firm's competitive strategies and information systems capabilities," Mis Quarterly, pp. 909-929, 2011.

[10] S. Gregor and A. R. Hevner, "Positioning and presenting design science research for maximum impact," MIS quarterly, pp. 337-355, 2013.

[11] N. Dabbagh and S. Dass, "Cats: A tool for identifying the cognitive affordances of learning technologies," thannual, p. 401, 2013.

[12] J. Gibson, "The ecological approach to visual perception. lawrence erblbaum associates," Inc., Hillsdale, 1986.

[13] D. A. Norman, "Affordance, conventions, and design," interactions, vol. 6, no. 3, pp. 38-43, 1999.

[14] B. Dalgarno and M. J. Lee, "Exploring the relationship between afforded learning tasks and learning benefits in $3 \mathrm{~d}$ virtual learning environments," in Proceedings of the 29th ASCILITE Conference, Wellington, New Zealand, vol. 2528, 2012, pp. 236245.
[15] S. Warburton, "Second life in higher education: Assessing the potential for and the barriers to deploying virtual worlds in learning and teaching," British journal of educational technology, vol. 40, no. 3, pp. 414-426, 2009.

[16] K. Andreas, T. Tsiatsos, T. Terzidou, and A. Pomport- sis, "Fostering collaborative learning in second life: Metaphors and affordances," Computers \& Education, vol. 55, no. 2, pp. 603-615, 2010.

[17] F. Ke, S. Lee, and X. Xu, "Teaching training in a mixed-reality integrated learning environment," Computers in Human Behavior, vol. 62, pp. 212-220, 2016.

[18] T. Roshko, J. Hare, and N. Layne, "Virtual reality environment as a learning tool in a graduate level interior design studio," The International Journal of Design Education, vol. 13, no. 4, pp. 39-49, 2019.

[19] O. Volkoff and D. M. Strong, "Critical realism and affordances: Theorizing it-associated organizational change processes," MIS quarterly, pp. 819-834, 2013.

[20] E. Karahanna, S. X. Xu, Y. Xu, and N. A. Zhang, "The needs-affordances-features perspective for the use of social media," Mis Quarterly, vol. 42, no. 3, pp. 737-756, 2018.

[21] J. G. Greeno, "Gibson's affordances.," Psychological Review, vol. 101, no. 2, pp. 336-342, 1994.

[22] A. Bhargava, K. M. Lucaites, L. S. Hartman, H. Solini, J. W. Bertrand, A. C. Robb, C. C. Pagano, and S. V. Babu, "Revisiting affordance perception in contemporary virtual reality," Virtual Reality, pp. 112, 2020.

[23] M. Leyrer, S. A. Linkenauger, H. H. Bulthoff, U. Kloos, and B. Mohler, "The influence of eye height and avatars on egocentric distance estimates in immersive virtual environments," in Proceedings of the ACM SIGGRAPH symposium on applied perception in graphics and visualization, 2011, pp. 67-74.

[24] Q. Lin, J. J. Rieser, and B. Bodenheimer, "Stepping off a ledge in an hmd-based immersive virtual environment," in Proceedings of the ACM Symposium on applied perception, 2013, pp. 107110.

[25] C. Chen, A. Seff, A. Kornhauser, and J. Xiao, "Deepdriving: Learning affordance for direct perception in autonomous driving," in Proceedings of the IEEE International Conference on Computer Vision, 2015, pp. 2722-2730.

[26] C. Craig, Understanding perception and action in sport: How can virtual reality technology help? sports technology, 6 (4), 161-169, 2013.

[27] J. J. Gibson, "The ecological approach to the visual perception of pictures," Leonardo, vol. 11, no. 3, pp. 227-235, 1978.

[28] A. Alshaer, H. Regenbrecht, and D. O'Hare, "Immersion factors affecting perception and behaviour in a virtual reality power wheelchair simulator," Applied ergonomics, vol. 58, pp. 1-12, 2017. 
[29] T. Y. Grechkin, J. M. Plumert, and J. K. Kearney, "Dynamic affordances in embodied interactive systems: The role of display and mode of locomotion," IEEE transactions on visualization and computer graphics, vol. 20, no. 4, pp. 596-605, 2014.

[30] S. W. Hong, J. Park, and M. Cho, "Virtual vs. actual body: Applicability of anthropomorphic avatars to enhance exploratory creativity in architectural design education," Architectural Science Review, vol. 62, no. 6, pp. 520-527, 2019.

[31] S. Invitto, C. Faggiano, S. Sammarco, V. De Luca, and L. T. De Paolis, "Haptic, virtual interaction and motor imagery: Entertainment tools and psychophysiological testing," Sensors, vol. 16, no. 3, p. 394, 2016.

[32] O. Mantziou, N. M. Papachristos, and T. A. Mikropoulos, "Learning activities as enactments of learning affordances in muves: A review-based classification," Education and Information Technologies, vol. 23, no. 4, pp. 1737-1765, 2018.

[33] D. M. Strong, O. Volkoff, S. A. Johnson, L. R. Pelletier, B. Tulu, I. Bar-On, J. Trudel, and L. Garber, "A theory of organization-ehr affordance actualization," Journal of the association for information systems, vol. 15, no. 2, p. 2, 2014.

[34] C. Girvan and T. Savage, "Identifying an appropriate pedagogy for virtual worlds: A communal constructivism case study," Computers \& Education, vol. 55, no. 1, pp. 342-349, 2010.

[35] J.-P. Tsai, Y.-C. Kao, and R.-S. Lee, "Investigating the effect of virtual reality application on teaching assistance for machine tools operation education," in 2012 IEEE/ASME International Conference on Advanced Intelligent Mechatronics (AIM), IEEE, 2012, pp. 626-631.

[36] L. Zheng, T. Xie, and G. Liu, "Affordances of virtual reality for collaborative learning," in 2018 International Joint Conference on Information, Media and Engineering (ICIME), IEEE, 2018, pp. 6-10.

[37] P. Diaz, T. Zarraonandia, M. Sa'nchez-Francisco, I. Aedo, and T. Onorati, "Do low cost virtual reality devices support learning acquisition? a comparative study of two different vr devices," in Proceedings of the XX International Conference on Human Computer Interaction, 2019, pp. 1-8.

[38] J. Hair, W. Black, B. Babin, and R. Anderson, Pearson new international edition: Multivariat data analysis. exploratory data analysis in business and economics, 2014.

[39] M. Allen, The SAGE encyclopedia of communication research methods. Sage Publications, 2017.

[40] B. Dalgarno and M. J. Lee, "What are the learning affordances of 3-d virtual environments?" British Journal of Educational Technology, vol. 41, no. 1, pp. 10-32, 2010.

[41] F. L. Schmidt and J. E. Hunter, "The validity and utility of selection methods in personnel psychology: Practical and theoretical implications of 85 years of research findings.," Psychological bulletin, vol. 124, no. 2, p. 262, 1998.
[42] T. Chamorro-Premuzic and B. Frankiewicz, "Does higher education still prepare people for jobs," Harvard Business Review, vol. 7, 2019.

[43] D. Ebert, S. Gupta, and F. Makedon, "Ogma: A virtual reality language acquisition system," in Proceedings of the 9th acm international conference on pervasive technologies related to assistive environments, 2016, pp. 1-5.

[44] N. R. Council et al., Education for life and work: Developing transferable knowledge and skills in the 21st century. National Academies Press, 2012.

[45] T. T. Baldwin and J. K. Ford," Transfer of training: A review and directions for future research," Personnel psychology, vol. 41, no. 1, pp. 63-105, 1988. 